\title{
Compliance of the recurrent renal stone former with current best practice guidelines
}

\author{
Derek Bos; Kevin Kim; Jen Hoogenes; Shahid Lambe; Bobby Shayegan; Edward D. Matsumoto
} McMaster University, Hamilton, ON, Canada

Cite as: Can Urol Assoc J 2017 Dec. 22; Epub ahead of print. http://dx.doi.org/10.5489/cuaj.4605

Published online December 22, 2017

$* * *$

\begin{abstract}
Introduction: Patient compliance to best practice guidelines is a significant factor in preventing renal stone recurrence. While patient compliance has been historically poor, there remains a paucity of data in the renal stone setting. We evaluated compliance of the recurrent renal stone former with current Canadian Urological Association (CUA) best practice guidelines.
\end{abstract}

Methods: A prospective, cross-sectional study design was used to evaluate patient compliance. Recurrent renal stone former patients were consecutively recruited from McMaster's Institute of Urology and completed a one-time questionnaire developed in accordance with CUA best practice guidelines. Questionnaire sections included: 1) demographics; 2) interaction(s) and satisfaction with their healthcare provider; and 3) knowledge, attitudes, and compliance with best practices.

Results: A total of 300 patients were enrolled in the study; $55.3 \%$ were men, $69.5 \%$ had a history of stone surgery, while $23.7 \%$ had a positive family history. Participants perceived satisfactory education from their urologist and primary care physician $82.7 \%$ and $59.7 \%$ of the time, respectively $(\mathrm{p}<0.05)$. Nearly a quarter of patients $(22.8 \%)$ perceived their stone disease to be severe and $67.1 \%$ of patients believed in the efficacy of preventative stone measures. Overall, $45.8 \%$ of patients were compliant with CUA best practice guidelines. The majority of patients (72.6\%) complied with high fluid intake, the most critical stone preventative practice.

Conclusions: Consistent with previous studies, compliance to dietary recommendations in this evaluation of recurrent stone formers was low. Study findings may be attributed to insufficient knowledge translation, lack of perceived disease severity, and/or patient uncertainty in the importance of preventative stone practices. 


\section{Introduction}

The increasing prevalence of nephrolithiasis is well recognized worldwide. Renal stone recurrence occurs in up to $50 \%$ of patients within the first five years following initial stone development. $^{1-2}$ Moreover, relapses occur more frequently and the time interval between each recurrence is shortened. ${ }^{2}$ Fortunately, stone clinics have shown that patients can reduce their five-year recurrence rate by as much as $60 \%$ with changes in lifestyle and dietary habits alone. ${ }^{3-4}$ Similar to many chronic medical conditions, these preventative practices are dependent on patient self-awareness, motivation, and ultimately, compliance. ${ }^{3}$

The recurrent nature of the disease often results in significant patient morbidity and burdensome healthcare expenditures. ${ }^{5-7}$ In the United States alone, the total cost associated with nephrolithiasis has been estimated to be as high as $\$ 5.3$ billion. ${ }^{8}$ This estimation not only includes the treatment of acute consequences of nephrolithiasis, such as pain, surgery, and hospitalization, but also the indirect costs such as loss of employment. ${ }^{8}$ Economic considerations related to stone disease are known to have a considerable impact on overall healthcare expenses.

Patient compliance has often been a challenge in the prevention and treatment of any chronic disease. It is estimated that as many as $75 \%$ of patients consistently fail to follow their clinicians' recommendations when it pertains to preventative health practices. ${ }^{9-10}$ Compliance rates across disease processes vary considerably, and have even shown to be poor for treatments that are deemed highly effective. ${ }^{9-11}$ Currently, there is a paucity of literature defining patient compliance to conservative treatment measures within the recurrent renal stone former population. Our study aimed to address this knowledge gap in the urological literature.

The study objective was to evaluate the recurrent stone formers' compliance with current Canadian Urological Association (CUA) best practice guidelines, while gaining insight into patients' understanding of preventative practices and the education they receive from healthcare providers.

\section{Methods}

In a single-group, prospective cross-sectional survey study, renal stone patients seen at the McMaster Institute of Urology located in Hamilton, ON, Canada, were enrolled from August 2015 to September 2016. Potential participants were identified and recruited during their scheduled clinic visit. Eligible participants were known renal stone formers (defined by two or more documented stone occurrences during his/her lifetime) and at least 18 years of age. A research assistant obtained informed consent from all eligible participants and distributed the questionnaire in the clinic waiting room. To limit bias, all surveys were completed prior to the patient-urologist interaction, and all participants were instructed that involvement in the study would not influence their care.

Basic survey methodology was used in questionnaire development (e.g., anchored Likert 
scales, multiple-choice, dichotomous, and short answer questions). The 21 survey questions were designed based on the current CUA best practice guidelines on stone preventative measures (see Appendix). ${ }^{12}$ The questionnaire consisted of three domains. The first included demographics, comorbidities, and previous stone management. The second domain covered previous clinician encounters due to kidney stones and patient satisfaction, while the third consisted of questions directed at patient knowledge, attitudes, and guideline compliance. Research ethics board approval was obtained prior to commencing the study.

The primary outcome measure was compliance of the recurrent renal stone former to the CUA best practice guidelines. Secondary outcome measures included the evaluation of participant characteristics that may influence compliance, including knowledge, education, frequency, and subjective quality of preventative education, perceived severity of their disease, prior stone interventions, and, if applicable, attitudes regarding efficacy of stone-related conservative treatments.

All participants were assigned an identification number to ensure anonymity, and consent forms were stored separately from the surveys. All quantitative data was analyzed via descriptive statistics using IBM SPSS Statistics 22 (IBM Corp, Armonk, NY, USA). Correlations were explored for variables within and between survey domains using the Chi-square test for categorical data and t-tests for ordinal data. All tests were two-sided, with a $p$-value of $<0.05$ defining statistical significance.

\section{Results}

\section{Participant characteristics}

A total of 300 patients were enrolled in the prospective study. Males comprised the majority of the cohort ( $n=166 ; 55.3 \%)$. The most frequent stone formers were in their $5^{\text {th }}$ and $6^{\text {th }}$ decade of life. Participant demographics are outlined in Table 1. Among the study population, 69.6\% of participants had a post-secondary education, while $27.3 \%$ of participants had a predisposing medical condition. A positive family history was present in $23.7 \%$ of the study population. Participants perceived their disease as severe 22.8\% of the time. Most participants (68.3\%) were unaware of their stone composition, though calcium-based stones were the most frequently declared. The majority of participants (69.5\%) had previously undergone surgical stone management. Participants more commonly interacted with their urologist in comparison to their primary care provider regarding stone management, with a mean visit frequency of 5.4 and 3.2, respectively.

\section{Attitudes and compliance}

Participants stated that they had satisfactory knowledge translation discussions with their urologist and primary care physician $82.7 \%$ and $59.7 \%$ of the time, respectively $(p<0.05)$ (Figure 1 ). When surveyed about their belief in preventative stone treatments, $67.1 \%$ of participants were 
in agreement that preventative practices reduce future stone occurrences (Figure 2).

Overall patient compliance to preventative stone practices, as outlined in the current CUA best practice guidelines, was $45.8 \%$. The highest compliance rate was to fluid intake (72.6\%). Calcium and salt intake compliance rates were $70.7 \%$ and $51.7 \%$, respectively. Compliance to both citrate and protein best practice recommendations were $13.9 \%$ and $19.2 \%$, respectively (Figure 3). Participant knowledge varied widely based on specific dietary recommendations. Participants demonstrated adequate understanding of fluid intake and its role in prevention; however, knowledge was lacking when assessing adjunct dietary measures (Figure 4). A significant association was demonstrated between frequency of education by treating urologist and compliance to preventative stone practices $(p<0.05)$.

\section{Discussion}

The literature on patient compliance to best practice recommendations has continued to grow rapidly over the past several decades as the prevalence of chronic disease has increased. ${ }^{9}$ Despite this shift, patients do not always adhere to their clinicians’ recommendations, which are primarily derived from published clinical practice guidelines. In addition to poor clinical outcomes and the potential for diminished patient quality of life, patient noncompliance can also be a large economic burden for the healthcare system. ${ }^{13-14}$ Although best practice guidelines have been published for treatment and prevention of recurrent renal stones, there is a gap in the literature that describes detailed compliance issues within the recurrent stone former population.

Our study depicts a poor compliance rate among recurrent renal stone formers with regards to current CUA best practice guidelines. While participants were highly compliant with the most critical preventative measure (fluid intake, $72.6 \%$ ), compliance rates were low when evaluating associated preventative dietary measures. The "stone clinic effect" and successive role of dietary measures in reducing stone recurrence rates is well described. ${ }^{15} \mathrm{~A}$ recent meta-analysis highlighted the importance of fluids in reducing stone recurrence, with a risk reduction in stone formation of $60-80 \% .{ }^{16}$ Unfortunately, less than $10 \%$ of high-risk renal stone patients undergo a metabolic evaluation. ${ }^{17}$ While fluid intake plays a crucial role in stone prevention, the literature suggests that patients who receive specific dietary recommendations based on a comprehensive evaluation have fewer stone recurrences than those who only received general dietary advice. ${ }^{18}$ The majority of our study participants (68.3\%) were unaware of their stone composition or predisposing metabolic condition, thereby limiting the efficacy of dietary treatment recommendations.

Renal stones are associated with high morbidity and pose a significant economic burden to any health care system. ${ }^{5}$ The rising incidence in associated medical comorbidities including both obesity and diabetes is expected to result in an increased stone management cost of \$1.24 billion dollars yearly in the United States by $2030 .{ }^{19}$ Increasing patient awareness and knowledge of preventative stone practices would improve both patient outcomes while concurrently 
reducing healthcare expenditures.

The majority of participants demonstrated confidence in the utility of preventative practices in stone prevention. Despite this confidence, compliance rates were marginal. This discrepancy may be due to a number of factors such as inadequate knowledge translation, interpersonal relationships, personal or cultural views, and/or lack of perceived disease severity. A patient's health literacy is central to his or her ability to comply. In a large study of over 2500 patients, nearly one-third had marginal or inadequate health literacy, while language barrier was an insignificant factor. ${ }^{20}$ Many studies confirm these trends and indicate that current interventions aimed at increasing health literacy to improve patient compliance have, to date, been relatively ineffective. ${ }^{21}$ The interpersonal dynamics of the patient-provider relationship play a vital role in determining a wide array of patient outcomes, including patient compliance to treatment recommendations. Patients who perceive satisfactory patient-provider communication while having a physician that empowers them to be active in their own care tend to be more motivated to adhere. ${ }^{22}$ Patient understanding of their recommendations and a healthy patientprovider relationship is not sufficient to eliminate the possibility of noncompliance, as patients' mindsets strongly influence their compliance. In our study population, less than $25 \%$ of participants perceived their disease as severe. If patients embrace opinions that are incongruent with those of their physician, they may have difficulty forming an enthusiasm or intention to be compliant.

Participants perceived satisfactory knowledge translation more often with their urologist, in contrast to their primary care provider. Based on healthcare provider clinical expertise, this study finding is not unexpected. The importance of visit frequency between patient and specialist and how it positively influences compliance was an intriguing outcome. It has been described that an important factor in noncompliance is patients' inability to remember the details of physician recommendations during clinic visits. ${ }^{23-24}$ Even during clinical encounters where information is communicated effectively and comprehension is initially high, much of what is conveyed is often forgotten within moments of leaving the physician's office. ${ }^{25}$ Perhaps frequent and effective clinic visits, along with the availability of health promotion literature for the patient, may be a worthwhile consideration during initial stone presentation to optimize preventative stone practices, potentially reducing future patient morbidity.

The limitations of our study deserve mention. It describes a cohort of patients at a single academic institution in Canada, thus potentially limiting its generalizability to other patient populations. By capturing information at one point in time using a cross-sectional design, this study is unable to establish causal relationships between measured variables. Further, recall bias is a notable limitation, as participants may have falsely stated their experience of prior educational encounters. The location of survey dissemination lends to the possibility of outcome bias. To limit bias, all participants completed the survey prior to their clinical encounter. Despite proceedings to circumvent social desirability bias, such as survey anonymity and equitable 
participant treatment regardless of participation, this bias is inherent. The questionnaire distributed to participants was not validated; however, two practicing urologists with subspecialty training in stone management formally reviewed the survey prior to recruitment. Furthermore, it is unknown whether patients in our study population had previously received written material regarding kidney stone prevention, and/or had previously searched elsewhere (e.g., Internet) for additional information. Following completion of the survey in clinic, patients received CUA kidney stone educational pamphlets. In the future, providing these pamphlets during every stone encounter in clinic can supplement the education received from the patient's urologist, perhaps improving knowledge and compliance to best practice guidelines.

\section{Conclusion}

In this single-centre prospective cross-sectional survey study, recurrent renal stone formers perceived satisfactory knowledge translation more often with their urologist when compared to their primary care provider; however, overall patient compliance to preventative best practice guidelines was poor. These findings are consistent with the broader medical literature as it pertains to patient compliance, yet adds to the lack of data available within the renal stone patient population. A future larger scale study may be of value in further understanding potential barriers to knowledge translation and ultimately compliance of the recurrent stone former.

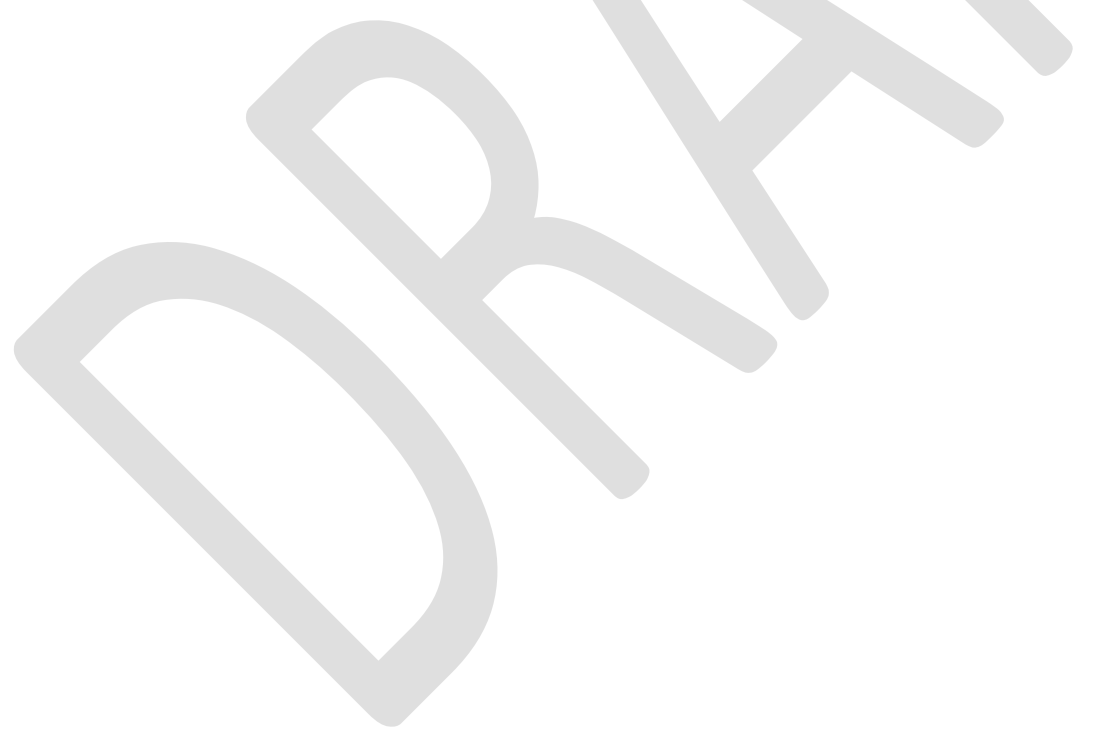




\section{References}

1. Lotan Y, Cadeddu JA, Roerhborn CG, Pak CY, Pearle MS. Cost-effectiveness of medical management strategies for nephrolithiasis. J Urol. 2004;172(6 Pt 1):2275-2281

2. Strauss AL, Coe FL, Deutsch L, Parks JH. Factors that predict relapse of calcium nephrolithiasis during treatment: a prospective study. Am J Med. 1982;72(1):17-24.

3. Fritsche HM, Dotzer K,. Improving the compliance of the recurrent stone-former. Arab $J$ Urol. 2012;10:342-346.

4. DiMatteo MR. Variations in patients' adherence to medical recommendations: a quantitative review of 50 years of research. Med Care. 2004;42(3):200-209.

5. Lotan Y, Buendia Jimenez I, Lenoir-Wijnkoop I, et al. Primary prevention of nephrolithiasis is cost-effective for a national healthcare system. BJU Int. 2012;110(11 Pt C):E1060-1067.

6. Romero V, Akpinar H, Assimos D (2010) Kidney stones: a global picture of prevalence, incidence, and associated risk factors. Rev Urol 12:e86-e96

7. Turney BW, Reynard JM, Noble JG, Keoghane SR (2012) Trends in urological stone disease. BJU Int 109:1082-1087

8. Saigal CS, Joyce G and Timilsina AR: Direct and indirect costs of nephrolithiasis in an employed population: opportunity for disease management? Kidney Int 2005; 68: 1808.

9. Balkrishnan R, Christensen DB, Bowton DL. Self-reported health status, prophylactic medication use, and healthcare costs in older adults with asthma. J Am Geriatr Soc. 2002;50(5):924-929.

10. DiMatteo MR, Haskard KB, Williams SL. Health beliefs, disease severity, and patient adherence: a meta-analysis. Med Care. 2007;45(6):521-528.

11. DiMatteo MR, Giordani PJ, Lepper HS, Croghan TW. Patient adherence and medical treatment outcomes: a meta-analysis. Med Care. 2002;40(9):794-811.

12. Pearle MS, Goldfarb DS, Assimos DG, et al. Medical management of kidney stones: AUA guideline. American Urological Association Guideline. March 2014.

13. Martin LR, Williams SL, Haskard KB, Dimatteo MR. The challenge of patient adherence. Ther Clin Risk Manag. 2005;1(3):189-199.

14. DiMatteo MR. Evidence-based strategies to foster adherence and improve patient outcomes. JAAPA. 2004;17(11):18-21.

15. Hosking DH, Erickson SB, Van den Berg CJ, et al. The stone clinic effect in patients with idiopathic calcium urolithiasis. J Urol 1983;130:1115-8.

16. Cheungpasitporn W, Rossetti S, Friend K, et al. Treatment effect, adherence, and safety of high fluid intake for the prevention of incident and recurrent kidney stones: a systematic review and meta-analysis. J Nephrol 2016;29:211-19.

17. Milose JC, Kaufman SR, Hollenbeck BK, et al. Prevalence of 24-hour urine collection in 
high-risk stone formers. J Urol 2014;191:376-80.

18. Kocvara R, Plasqura P, Petrik A, et al. A prospective study of nonmedical prophylaxis after a first kidney stone. BJU Int 1999;84:393-8.

19. Antonelli JA, Maalouf NM, Pearle MS, et al. Use of the National Health and Nutrition Examination Survey to calculate the impact of obesity and diabetes on cost and prevalence of urolithiasis in 2030. Eur Urol 2014;66:724-9.

20. Williams MV, Baker DW, Parker RM, et al. 1998. Relationship of functional health literacy to patients' knowledge of their chronic disease. A study of patients with hypertension and diabetes. Arch Intern Med, 158: 166-72.

21. Schillinger D, Grumbach K, Piette J, et al. 2002. Association of health literacy with diabetes outcomes. JAMA, 288:475-82.

22. O’Malley AS, Forrest CB, Mandelblatt J. 2002. Adherence of low-income women to cancer screening recommendations. J Gen Intern Med, 17:144-54.

23. Shemesh E, Shneider BL, Savitzky JK, et al. Medication adherence in pediatric and adolescent liver transplant recipients. Pediatrics. 2004;113:825-32

24. Zaghloul SS, Goodfield MJ. Objective assessment of compliance with psoriasis treatment. Arch Dermatol. 2004;140:408-14.

25. Ley P, Spelman MS. Communications in an out-patient setting. Br J Soc Clin Psychol. 1965;4:114-16. 


\section{Figures and Tables}

Fig. 1. The association between participant satisfaction and healthcare provider.

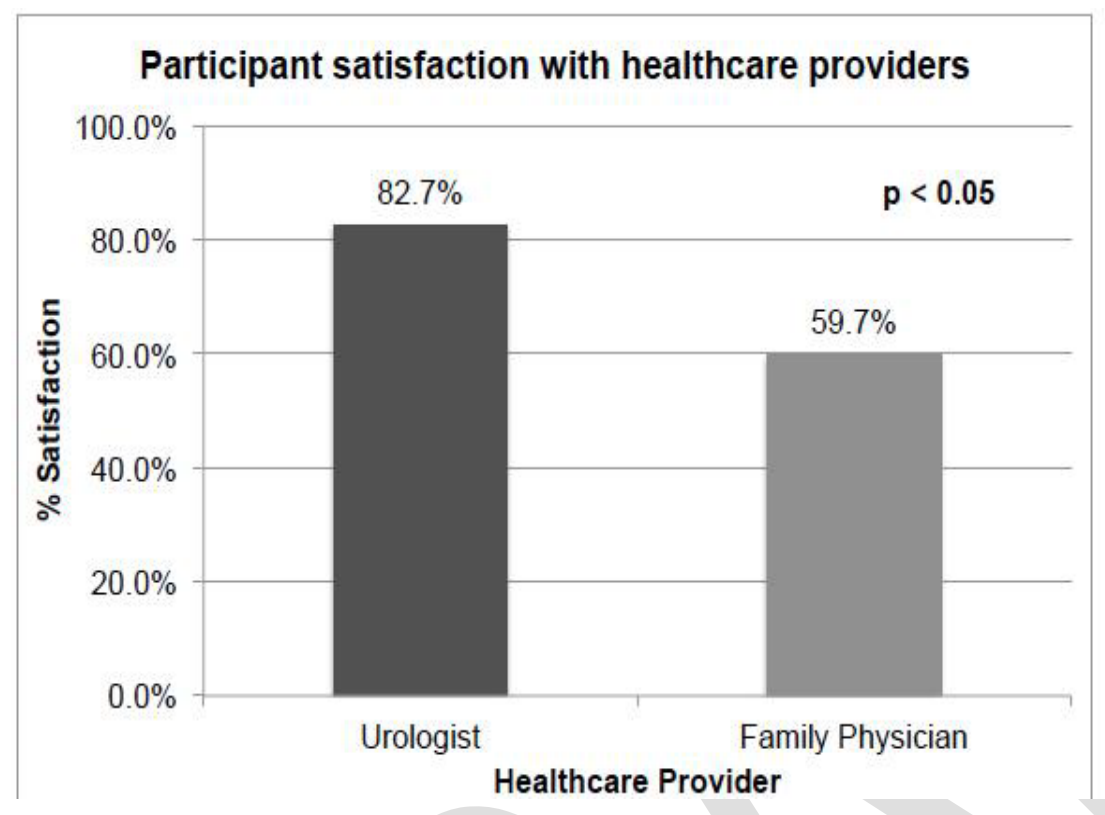

Fig 2. Participant confidence in the value of preventative stone measures.

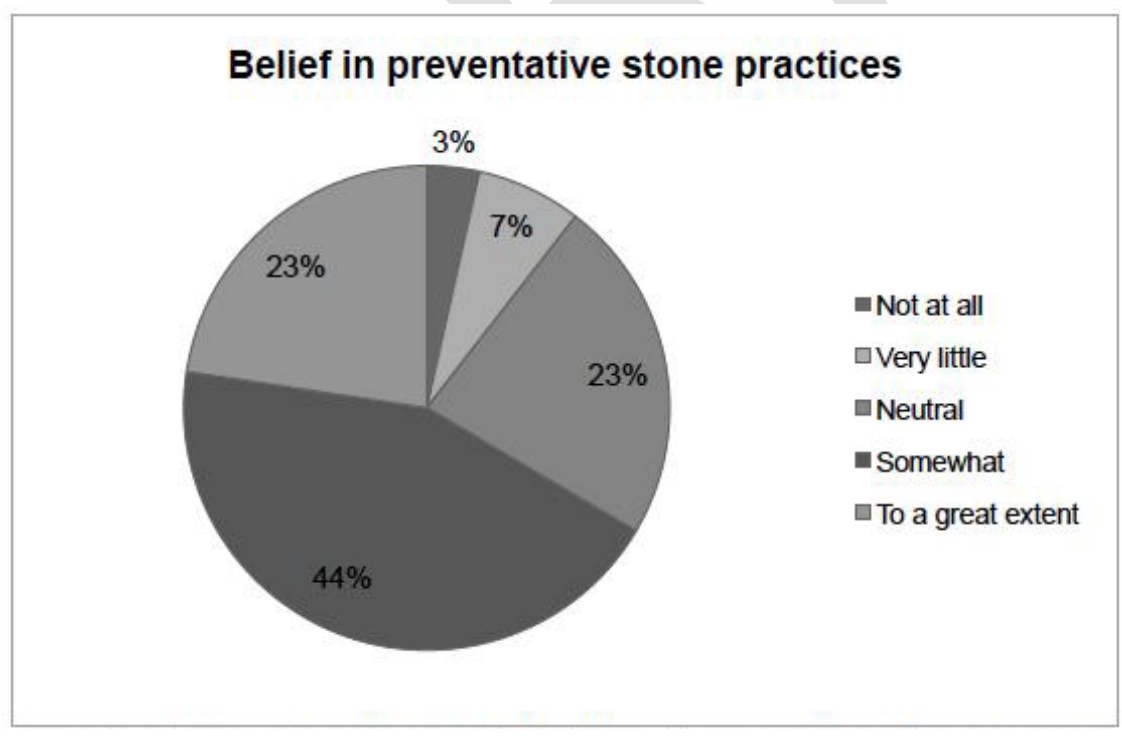


Fig. 3. Participant compliance with preventative practices.

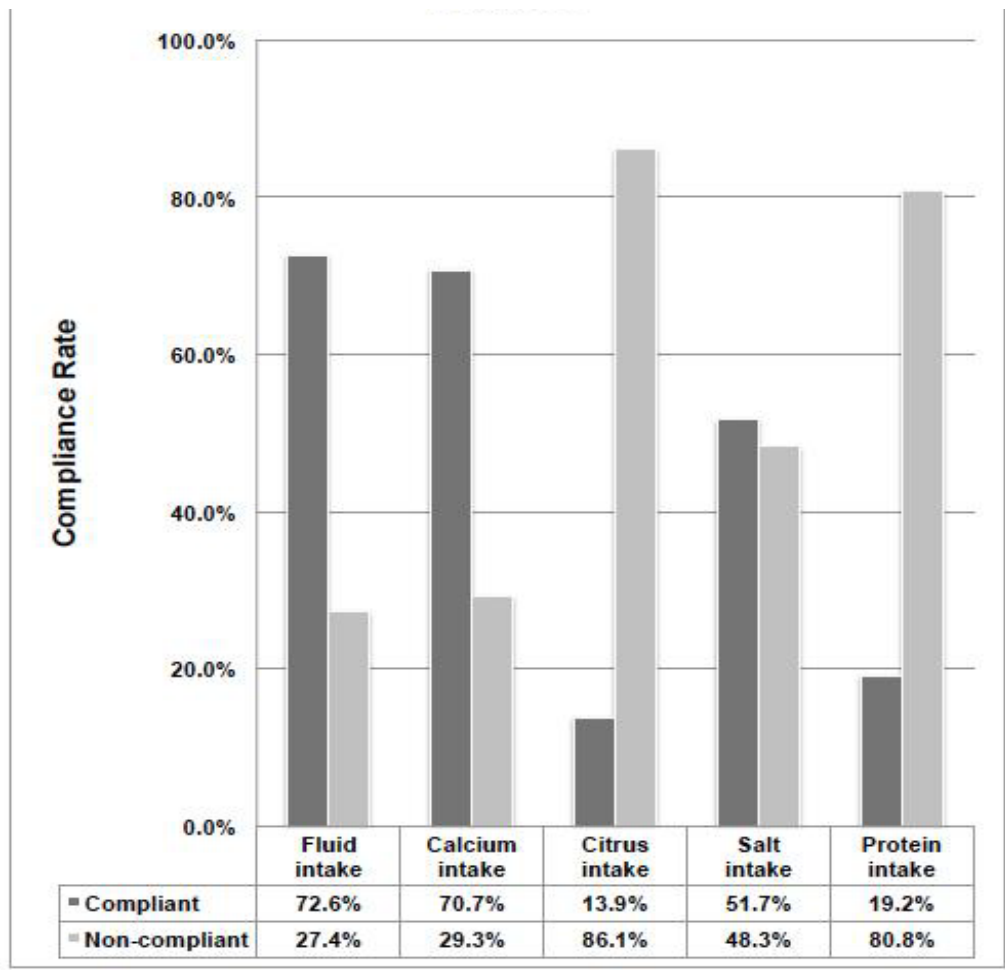

Fig. 4. Participant knowledge of preventative stone practices.

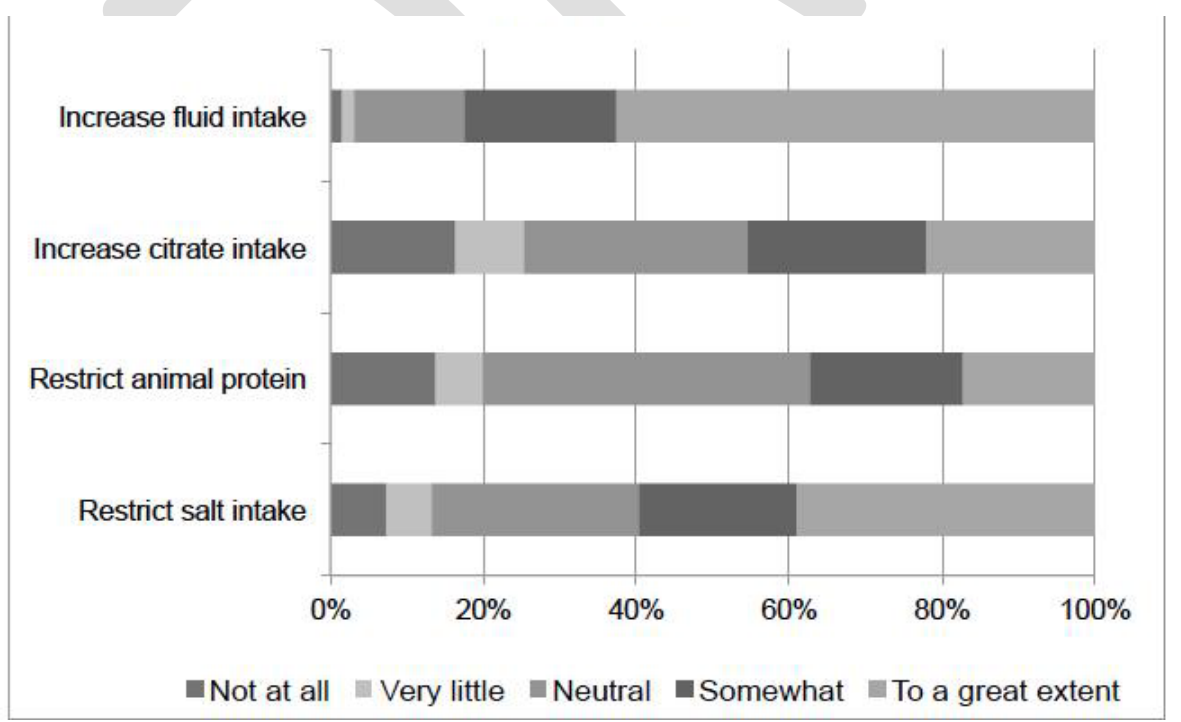




\begin{tabular}{|c|c|}
\hline Baseline characteristic & n (\%) \\
\hline \multicolumn{2}{|l|}{ Age (range) } \\
\hline $18-25$ & $2.7(8)$ \\
\hline $26-40$ & $11.3(34)$ \\
\hline $41-60$ & $47(141)$ \\
\hline $61+$ & $39(117)$ \\
\hline Gender & \\
\hline Male & $55.3(166)$ \\
\hline Female & $44.7(134)$ \\
\hline Level of education & 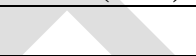 \\
\hline High school & $30.3(91)$ \\
\hline College & 39.0 (117) \\
\hline University & $20.3(61)$ \\
\hline Post-graduate & $10.3(31)$ \\
\hline Predisposing medical condition & 2 \\
\hline Inflammatory bowel disease & $4.0(11)$ \\
\hline Hyperparathyroidism & $1.8(5)$ \\
\hline Medullary sponge kidney & $3.3(9)$ \\
\hline Adult polycystic kidney disease & $0.7(2)$ \\
\hline Sarcoidosis & $0.4(1)$ \\
\hline Gout & $2.9(8)$ \\
\hline Diabetes & $14.2(39)$ \\
\hline \multicolumn{2}{|l|}{ Family history of stone disease } \\
\hline 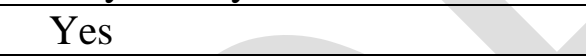 & $23.7(72)$ \\
\hline No & $76.3(228)$ \\
\hline \multicolumn{2}{|c|}{\begin{tabular}{l|l} 
Type of kidney stones &
\end{tabular}} \\
\hline Calcium oxalate & $21.7(63)$ \\
\hline Calcium phosphate & $1.7(5)$ \\
\hline Uric acid & $7.2(20)$ \\
\hline Cystine & $1.0(3)$ \\
\hline Unsure & $68.3(198)$ \\
\hline \multicolumn{2}{|l|}{ Prior stone surgery } \\
\hline Yes & $69.5(207)$ \\
\hline No & $30.5(91)$ \\
\hline \multicolumn{2}{|l|}{ Number of prior urologist encounters } \\
\hline 0 & $3.6(9)$ \\
\hline 1 & $20.4(51)$ \\
\hline $2-5$ & $48.4(121)$ \\
\hline $6-10$ & $16.0(40)$ \\
\hline $11+$ & $11.6(29)$ \\
\hline
\end{tabular}




\section{Assessing the knowledge and practices of the recurrent kidney stone-former}

1) Age (years):
a. $18-20$
e. $41-50$
b. $21-25$
f. $51-60$
c. $26-30$
g. $61-70$
d. $31-40$
h. $70+$

2) Sex:
a. $\mathrm{F}$
b. $\mathrm{M}$

3) What is your highest level of education?
a. Did not complete high school
b. High school diploma/GED
c. Some college
d. College graduate (diploma)
e. Some university
f. University graduate (bachelor's degree)
g. Post-graduate school (i.e., master's degree, M.D., Ph.D.)

4) Current medical conditions (if known - please circle all that apply to you):
a. Inflammatory bowel disease (Crohn's Disease/ulcerative colitis)
b. Hyperparathyroidism
c. Medullary sponge kidney
d. Adult polycystic kidney disease
e. Sarcoidosis
f. Type 1 renal tubular acidosis
g. Other(s), please specify:

5) Do you have a family history of kidney disease (immediate family members)?
a. Yes
b. No
c. Unsure

6) What type of stones do you form (if known)?
a. Calcium oxalate
b. Calcium phosphate
c. Uric acid
d. Cystine
e. Magnesium ammonium phosphate
f. Ammonium acid urate
g. Other:
h. Don't know/unsure
i. Comments 
7) When were you first diagnosed with kidney stone disease (year)?

8) Have you ever had surgery and/or shockwave lithotripsy to treat your kidney stones?

a. Yes

b. No

c. If yes, how many times have you had to have your stones surgically removed?

d. Comments

9) Approximately how many encounters have you had with each clinician regarding your kidney stones:
a. Family physician:
b. ER physician:
c. Urologist:
d. Dietician:

10) How satisfied are you with the education that you have received about preventing kidney stones? (Please check the box)

Very Unsatisfied

\begin{tabular}{|l|l|l|l|l|l|l|}
\multicolumn{5}{c}{ Unsatisfied } & Unsatisfied & Neutral \\
\hline Family Physician & & & & & & \\
\hline ER Physician & & & & & & \\
\hline Dietician & & & & & & \\
\hline Urologist & & & & & \\
\hline Other sources & & & & & & \\
\hline
\end{tabular}

Specify other sources

11) When you see each of the following clinicians, how often do they educate you on the following preventative measures for kidney stones (please check the box)?

\begin{tabular}{|l|c|c|c|c|c|c|}
\cline { 2 - 6 } \multicolumn{1}{c|}{ Family Physician } & Always & Usually & $\begin{array}{c}\text { About half the } \\
\text { time }\end{array}$ & Seldom & Never & N/A \\
\hline Fluid Intake & & & & & & \\
\hline Calcium Intake & & & & & & \\
\hline Protein Intake & & & & & & \\
\hline Citrate Intake & & & & & & \\
\hline Oxalate Intake & & & & & & \\
\hline Salt Intake & & & & & & \\
\hline
\end{tabular}

\begin{tabular}{|l|c|c|c|c|c|c|}
\cline { 2 - 6 } \multicolumn{1}{l|}{ ER Physician } & Always & Usually & $\begin{array}{c}\text { About half the } \\
\text { time }\end{array}$ & Seldom & Never & N/A \\
\hline Fluid Intake & & & & & & \\
\hline Calcium Intake & & & & & & \\
\hline Protein Intake & & & & & & \\
\hline Citrate Intake & & & & & & \\
\hline Oxalate Intake & & & & & & \\
\hline Salt Intake & & & & & & \\
\hline
\end{tabular}




\begin{tabular}{|l|c|c|c|c|c|c|}
\cline { 2 - 7 } \multicolumn{1}{c|}{} & Always & Usually & $\begin{array}{c}\text { About half the } \\
\text { time }\end{array}$ & Seldom & Never & N/A \\
\hline Fluid Intake & & & & & & \\
\hline Calcium Intake & & & & & & \\
\hline Protein Intake & & & & & & \\
\hline Citrate Intake & & & & & & \\
\hline Oxalate Intake & & & & & & \\
\hline Salt intake & & & & & & \\
\hline
\end{tabular}

\begin{tabular}{|l|c|c|c|c|c|c|}
\cline { 2 - 7 } \multicolumn{1}{c|}{ Dietician } & Always & Usually & $\begin{array}{c}\text { About half } \\
\text { the time }\end{array}$ & Seldom & Never & N/A \\
\hline Fluid Intake & & & & & & \\
\hline Calcium Intake & & & & & & \\
\hline Protein Intake & & & & & & \\
\hline Citrate Intake & & & & & & \\
\hline Oxalate Intake & & & & & & \\
\hline Salt Intake & & & & & & \\
\hline
\end{tabular}

\section{Comments}

12) To what extent do the following treatment measures prevent kidney stones?

\begin{tabular}{|l|l|l|l|l|c|}
\cline { 2 - 6 } \multicolumn{1}{c|}{} & Not at all & Very Little & Neutral & Somewhat & $\begin{array}{c}\text { To a great } \\
\text { extent }\end{array}$ \\
\hline High fluid intake & & & & & \\
\hline High calcium intake & & & & & \\
\hline Restricted animal protein diet & & & & & \\
\hline $\begin{array}{l}\text { High citrate intake (i.e. lemonade, } \\
\text { orange juice }\end{array}$ & & & & & \\
\hline Low salt intake & & & & & \\
\hline $\begin{array}{l}\text { High oxalate diet (i.e. spinach, } \\
\text { nuts, chocolate, tea) }\end{array}$ & & & & & \\
\hline
\end{tabular}

The following questions are to assess your routine behaviours and the answers should reflect what you do on a daily basis to prevent recurrence of kidney stones:

\section{Regarding fluid intake, I:}

a. Restrict fluid intake to less than $1 \mathrm{~L}$ per day

b. Drink 1L cranberry juice per day

c. Drink enough fluid, so that my urine is clear and output is approximately 2-3L per day

d. Have not changed the amount of liquid that I drink

\section{Regarding protein intake, I have:}

a. Increased my total protein intake

b. Restricted my animal protein intake

c. Restricted my vegetable protein intake

d. Not restricted my protein intake 
3. Regarding calcium intake, I have:

a. Restricted my calcium intake

b. Maintained a normal calcium intake

c. Increased my calcium supplement intake

d. Increased my dietary calcium intake

4. Regarding citrus intake, I have:

a. Restricted my citrus intake

b. Maintained my usual citrus intake

c. Increased my citrus intake

5. Regarding salt intake, I have:

a. Increased my salt intake

b. Maintained my usual salt intake

c. Restricted my salt intake

6. If you currently take medications to help with kidney stone prevention (i.e. hydrochlorothiazide, allopurinol, and others), I take the medication:
a. Never
b. Rarely
c. Occasionally
d. Frequently
e. Always

7. How would you rate the severity of your kidney stone disease?
a. Not a problem
b. Mild problem
c. Moderate problem
d. Severe problem
e. Very severe problem

8. Do you believe that conservative treatments prevent kidney stones (i.e. diet, medication)?
a. Not at all
b. Very little
c. Neutral
d. Somewhat
e. To a great extent

Comments: 